\title{
Hydro-chemical evolution of groundwater and mixing between aquifers: a statistical approach based on major ions
}

\author{
Linhua Sun · Herong Gui
}

Received: 3 October 2013/Accepted: 23 February 2014/Published online: 14 March 2014

(C) The Author(s) 2014. This article is published with open access at Springerlink.com

\begin{abstract}
Geochemical analysis is a useful tool in hydrogeological assessment, particularly in constructing a conceptual model of a hydrogeological system. In this study, major ion concentrations of 53 groundwater samples from the coal-bearing aquifer in the Qidong coal mine, northern Anhui Province of China have been processed by statistical analysis for understanding either hydro-chemical characteristics or hydrological evolution, which will be useful for the safety of coal mining. The results suggest that most of the samples are $\mathrm{Na}-\mathrm{SO}_{4}$ and $\mathrm{Na}-\mathrm{HCO}_{3}$ types, and their hydro-chemical compositions are mainly controlled by dissolution of more soluble minerals (e.g. calcite) and weathering of silicate minerals (e.g. plagioclase). Two groups of samples have been subdivided by quantile and scatter plots of factor scores, one is related to different degrees of water-rock interactions and another is related to groundwater mixing. Moreover, four end members have been identified and the mixing calculation suggests that the groundwater samples affected by mixing have $20-100 \%$ contribution from the loose layer aquifer (LA), and therefore, groundwater from the LA in the coal mine should be taken seriously during coal mining. The study demonstrated that statistical analysis is useful for connecting the hydrochemistry of groundwater with hydrological evolution of the aquifer.
\end{abstract}

Keywords Groundwater $\cdot$ Hydrochemistry $\cdot$ Statistical analysis $\cdot$ Water-rock interaction $\cdot$ Mixing $\cdot$ Coal mine

L. Sun $(\bowtie) \cdot$ H. Gui

School of Earth Science and Engineering, Suzhou University, Suzhou 234000, Anhui, China

e-mail: sunlinh@126.com

\section{Introduction}

Understanding the mixing between groundwater and other water bodies is an important work for groundwater management, because it is a common phenomenon and important process governing groundwater chemistry in many natural systems, and a large number of studies have been processed (Schramke et al. 1996; Johannesson et al. 1997; Laaksoharju et al. 1999, 2008; Rueedi et al. 2005; Long and Valder 2011; Valder et al. 2012; Morales-Casique 2012). Among these studies, geochemistry is considered to be a useful tool in hydrogeological assessment, particularly in constructing a conceptual model of a hydrogeological system. Previous studies revealed that the chemical compositions of groundwater are controlled by complex processes (e.g. recharge, reaction and mixing). However, in some situations, mixing can explain the leading order variability in geochemical composition, while chemical reactions explain the remaining variability (Laaksoharju et al. 1999, 2008; Morales-Casique 2012).

Mixing calculations based on hydrochemistry have been successfully applied in several hydrogeological settings for better understanding of the hydrological evolution. Taking for instance, mixing of three end members related to shallow and deep groundwater systems have been postulated by Ramos-Leal et al. (2007) for explaining the geochemical variations in an aquifer of Central Mexico, whereas mixing has been applied for understanding the hydro-chemical evolutions in Sweden and Canada in combination with water-rock interactions (Laaksoharju et al. 2008). A detailed review of other applications of mixing calculations can be found in Nakaya et al. (2007). These studies demonstrated that the concentration of solutes of mixtures between two end members follows a linear relation, while chemical reactions of reactive constituents introduce significant nonlinear effects (Wigley and Plummer 1976).

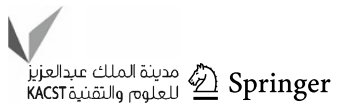


Hydrogeological studies of groundwater are important work in coal mines, because they can provide information to understand the hydrological evolution of the area, which is essential for water disaster controlling during coal mining (e.g. water source identification after water inrush). Therefore, a large number of hydro-chemical studies including major ions, rare earth elements and stable isotopes have long been carried out in northern Anhui Province of China, as the area is an important energy base with huge coal production every year (more than 30 million tons) (e.g. Gui and Chen 2007, Gui et al. 2011; Sun et al. 2011, Sun and Gui 2012). However, the groundwater mixing between aquifers has not been well-understood, which is important for water inrush controlling in coal mines (e.g. multi-water source identification) (Sun 2013).

In this study, we report a case study in the Qidong coal mine, northern Anhui Province, China. The major ion concentrations of groundwater samples from the coal-bearing aquifer (CA) have been processed by statistical analysis and mixing model. The goals of this study include: (1) understanding the hydro-chemical characteristics of the groundwater and (2) identifying the end members affecting the chemical compositions of groundwater. The study can provide useful information for understanding the hydrological evolution of the aquifer. Moreover, it is important for future water disaster controlling in the coal mine because it can reveal the potential hydraulic connection between aquifers.

\section{Site description}

The Qidong coal mine is located $20 \mathrm{~km}$ south to Suzhou City, northern Anhui Province of China and belongs to Suxian coal field (Fig. 1). The width of the coal mine is
$3-8 \mathrm{~km}$ from south to north, and the length is $10-13 \mathrm{~km}$ from east to west, the total area is $47.3 \mathrm{~km}^{2}$. The climate in the area is warm and semi-humid. The annual average temperature is $14.4{ }^{\circ} \mathrm{C}$ and the average annual rainfall is $834 \mathrm{~mm}$, most of which concentrates between July and August.

Previous explorations revealed that the groundwater system in the mine can be divided into three major aquifer systems from shallow to deep: loose layer aquifer system (LA), coal-bearing sandstone aquifer system (CA) and the underlying limestone aquifer system (TA). Each major aquifer system can be subdivided into certain small secondary aquifers and their characteristics are as follows:

LA: containing four secondary aquifers. The first aquifer is buried in shallow environment $(<40 \mathrm{~m})$ and the wall rocks are dominated by siltstone and clay. The second aquifer is located between 78 and $101 \mathrm{~m}$ depth and the main rock types in the aquifer are siltstone and fine sandstone. The third aquifer is buried between the depth of 185 and $200 \mathrm{~m}$ and the host rocks are mainly composed of siltstone and median sandstone. The depth of the fourth aquifer is $285-400 \mathrm{~m}$ and the wall rocks are mainly composed of conglomerate, sandstone and siltstone. Quartz sandstone, limestone, flint are main constitutes in the conglomerates. The fourth aquifer is considered to be a potential threat for coal mining, as it has been proven to be the water supplier for the water inrush in 2011 (Gui and Chen 2007).

CA: three secondary aquifers have been subdivided. The first one is named as K3 aquifer, which is mainly composed of gray-white median and fine sandstones with a thickness of $12 \mathrm{~m}$, and the coals related to it include 1st, 2nd and 3rd coal seams. The second aquifer is related to 7 th-9th coal seams, the main rock types are median and fine sandstones.
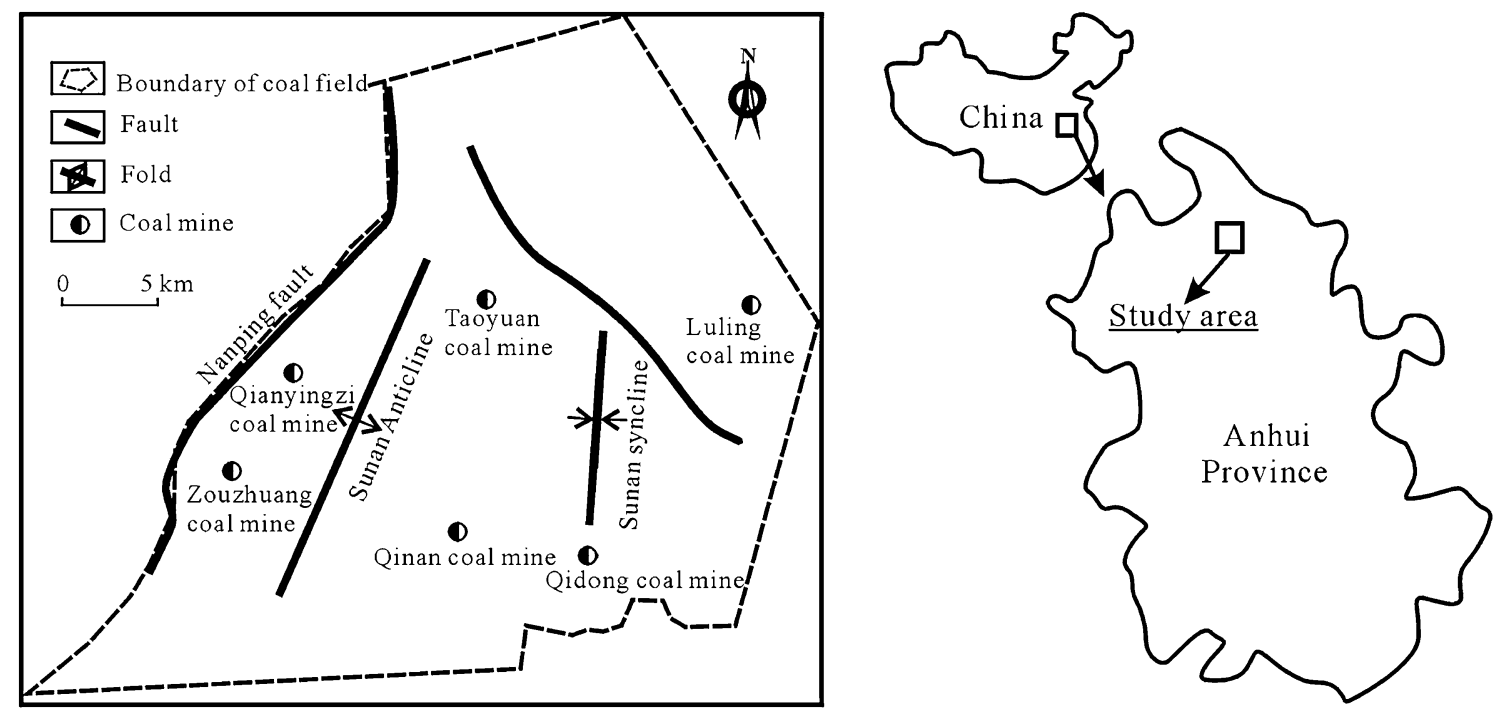

Fig. 1 Location of the Qidong coal mine 
The third one is a 10th coal seam related aquifer, which is composed of fine sandstones with siltstone and clay. In summary, CA is a close aquifer system and has limited water storage.

TA: two secondary limestone aquifers have been identified in the aquifer system, including the upper Taiyuan TA and lower Ordovician TA. The total thickness of the Taiyuan Formation is $193 \mathrm{~m}$ and there are 14 layers of limestone with a total thickness of $83 \mathrm{~m}$. The water is stored in the dissolution-related caves. During the mining of the 10th coal seam, the water from TA is considered to be a threat to coal mining safety, due to the close distance between 10 th coal seam and TA.

\section{Materials and methods}

All of the samples were collected from the tunnel of coal mining in the Qidong coal mine during Jan 2011 and Dec 2011. A total of 53 samples have been collected and they were related to the $3 \mathrm{rd}$, 4 th and 6 th-9th coal seams. Concentrations of seven kinds of major ions $\left(\mathrm{Na}^{+}, \mathrm{Ca}^{2+}\right.$, $\mathrm{Mg}^{2+}, \mathrm{Cl}^{-}, \mathrm{SO}_{4}{ }^{2-}, \mathrm{HCO}_{3}{ }^{-}$and $\left.\mathrm{CO}_{3}{ }^{2-}\right), \mathrm{pH}$ values and total dissolved solids (TDS) have been analyzed, and the analytical methods are as follows: $\mathrm{Na}^{+}, \mathrm{Ca}^{2+}, \mathrm{Mg}^{2+}, \mathrm{Cl}^{-}$ and $\mathrm{SO}_{4}{ }^{2-}$ were analyzed by ion chromatography, whereas $\mathrm{HCO}_{3}{ }^{-}$and $\mathrm{CO}_{3}{ }^{2-}$ were analyzed by acid-base titration in the Engineering and Technological Research Center of Coal Exploration, Anhui Province, China.

Major ion concentrations were first processed by Aquachem (version 3.7) for classification of hydro-chemical facies. Factor analysis with maximum likelihood extraction in SPSS (version 16) was performed for understanding the source of major ions in combination with quantile plots $(Q-Q$ plots) of major ion concentrations. Moreover, $Q-Q$ and scatter plots of factor scores were used for sample grouping, and the end members responsible for the hydro-chemical compositions of the groundwater samples were identified by scatter plots of factor scores with extreme values in combination with hydrological conditions of the coal mine, as well as correlation between major ions, similar to the principle component analysis as reported by Laaksoharju et al. (2008). Moreover, a linear calculation of factor scores of end members was used for quantifying the mixing status of the groundwater samples.

\section{Results and discussions}

\section{Hydro-chemical compositions}

The statistics of hydro-chemical compositions of groundwater samples in this study are listed in Table 1. As can be seen from the table, most of the groundwater samples are dominated by $\mathrm{Na}^{+}$over other cations, whereas $\mathrm{HCO}_{3}{ }^{-}$and $\mathrm{SO}_{4}{ }^{2-}$ are the dominant anions. Moreover, all of the major ions have high coefficients of variations (Table 1), indicating that the hydro-chemical compositions of the samples show a high variability among the study area. In comparison with previous studies in the study area (e.g. Sun and Gui 2012), the groundwater samples in this study have lower $\mathrm{Na}^{+}, \mathrm{Cl}^{-}$and $\mathrm{HCO}_{3}{ }^{-}$, but higher $\mathrm{Ca}^{2+}, \mathrm{Mg}^{2+}$ and $\mathrm{SO}_{4}{ }^{2-}$ than the groundwater samples from the similar CA in the Renlou coal mine, indicating different hydrological conditions (rocks and water rock interactions).

Based on the classification of the Piper and Durov diagrams (Fig. 2), all of the groundwater samples in this study can be subdivided into four kinds of hydro-chemical facies: including $\mathrm{Ca}-\mathrm{SO}_{4}(4), \mathrm{Na}-\mathrm{Cl}(3), \mathrm{Na}_{-} \mathrm{SO}_{4}$ (21) and $\mathrm{Na}-$ $\mathrm{HCO}_{3}$ (25). It can also be obtained from Fig. 2 that the groundwater samples in this study can be classified into two groups with different chemical signatures: the first one (G1) is dominated by $\mathrm{Na}-\mathrm{HCO}_{3}$ and $\mathrm{Na}-\mathrm{Cl}$ types, which is considered to be representative of groundwater in the $\mathrm{CA}$, whereas group two with higher $\mathrm{Ca}^{2+}, \mathrm{Mg}^{2+}$ and $\mathrm{SO}_{4}{ }^{2-}$ concentrations is considered to be affected by other

Table 1 Statistics of hydro-chemical compositions (mg/L) of groundwater samples

\begin{tabular}{|c|c|c|c|c|c|c|c|c|c|}
\hline & $\mathrm{pH}$ & $\mathrm{Na}^{+}$ & $\mathrm{Ca}^{2+}$ & $\mathrm{Mg}^{2+}$ & $\mathrm{Cl}^{-}$ & $\mathrm{SO}_{4}{ }^{2-}$ & $\mathrm{HCO}_{3}^{-}$ & $\mathrm{CO}_{3}{ }^{2-}$ & TDS \\
\hline$N$ & 53 & 53 & 53 & 53 & 53 & 53 & 53 & 53 & 53 \\
\hline Min & 5.6 & 204 & 0 & 4 & 113 & 2 & 255 & 0 & 735 \\
\hline Max & 9.7 & 940 & 203 & 106 & 256 & 1,506 & 1,358 & 409 & 2,781 \\
\hline Mean & 8.2 & 380 & 69 & 45 & 202 & 380 & 581 & 37 & 1,404 \\
\hline SD & 0.68 & 175 & 71 & 39 & 49 & 348 & 258 & 72 & 434 \\
\hline $\mathrm{CV}$ & 0.08 & 0.46 & 1.04 & 0.86 & 0.24 & 0.92 & 0.44 & 1.93 & 0.31 \\
\hline$p$ value test & $<0.01$ & $<0.01$ & $<0.01$ & $<0.01$ & $<0.01$ & $<0.01$ & $<0.01$ & $<0.01$ & $<0.01$ \\
\hline RL & & 731 & 22.3 & 17.9 & 566 & 72.2 & 915 & 41.0 & \\
\hline
\end{tabular}

$S D$ and $C V$ mean standard deviation and coefficient of variation, respectively. $p$ value obtains from Anderson-Darling test. $R L$ is the mean concentration of groundwater samples from the CA in Renlou coal mine (after Sun and Gui 2012) 
Fig. 2 Piper and Durov diagrams

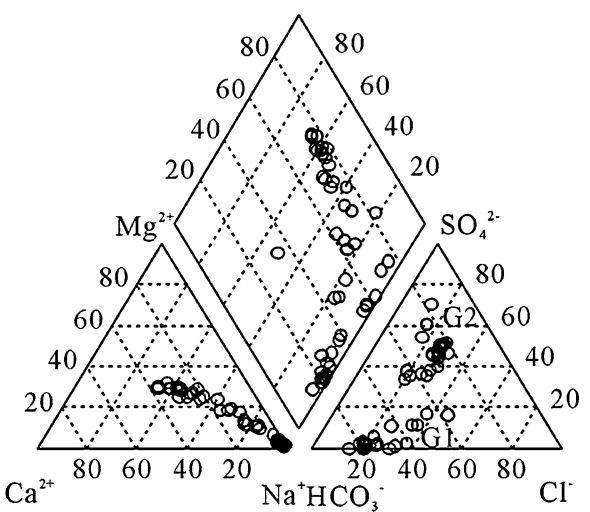

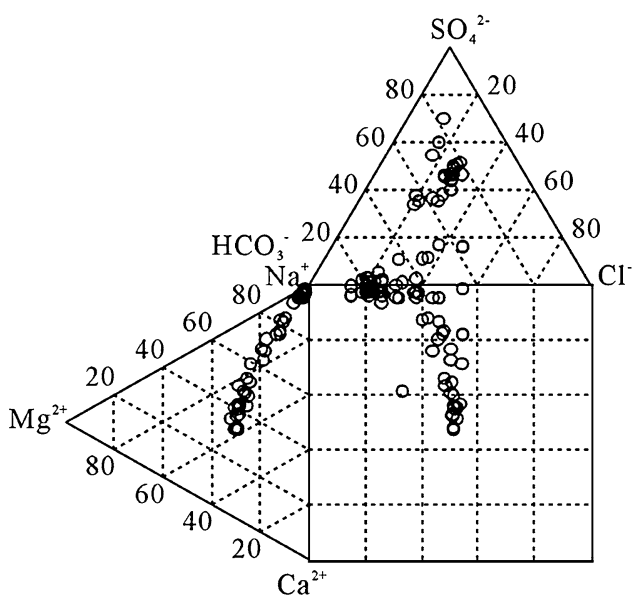

aquifers (see below). Moreover, Fig. 2 also gives information that their chemical characteristics are affected by three end members with $\mathrm{HCO}_{3}{ }^{-}, \mathrm{SO}_{4}{ }^{2-}$ and $\mathrm{Cl}^{-}$enrichment, respectively.

Source of major ions

Previous studies revealed that probability graphs of element concentrations are good indicators of sources (Reimann et al. 2005). In this study, more than one inflection points have been identified for all of the major ion concentrations (Fig. 3), implying that all of these major ions have more than one source. Take an instance, two sources are considered to be responsible for the variation of $\mathrm{Na}^{+}$ concentrations because one inflection point can be identified from the $Q-Q$ plot of $\mathrm{Na}^{+}$concentrations. This conclusion is further supported by their $p$ values of AndersonDarling test that no major ion has $p$ values higher than 0.05 (under $95 \%$ confidence, Table 1).

Factor analysis is a commonly used statistical method. It has been used for classification, simplification of the data and finding the most important variables in the data set. During geochemical studies, factor analysis has long been used for tracing elemental sources (e.g. Cloutier et al. 2008; Zhou et al. 2008; Yalcin et al. 2010). In this study, factor analysis is processed using the major ion concentrations $\left(\mathrm{Na}^{+}, \mathrm{Ca}^{2+}, \mathrm{Mg}^{2+}, \mathrm{Cl}^{-}, \mathrm{SO}_{4}{ }^{2-}\right.$ and $\left.\mathrm{HCO}_{3}{ }^{-}\right)$, and the result is shown in Fig. 4. Two factors with initial eigen value higher than one have been obtained.

After varimax rotation, the total variance explanation is $77.2 \%$. The first factor (FA 1) accounts for $41.4 \%$ of the total explanation and is dominated by $\mathrm{Ca}^{2+}, \mathrm{Mg}^{2+}, \mathrm{Cl}^{-}$and $\mathrm{SO}_{4}{ }^{2-}$, whereas the second factor (FA 2) accounts for $35.8 \%$ information and is dominated by $\mathrm{Na}^{+}$and $\mathrm{HCO}_{3}{ }^{-}$. This result is similar to the results obtained from the Renlou (Sun and Gui 2012) and the Wolonghu coal mine (Sun 2013). In combination with the wall rock compositions in the study area, as well as the understanding of previous studies, the FA 1 is considered to be representative of dissolution of more soluble minerals, such as calcite, dolomite and chloride, whereas the FA 2 is considered to be weathering of silicate mineral because only weathering of silicate minerals can generate $\mathrm{Na}^{+}$(e.g. plagioclase) and $\mathrm{HCO}_{3}{ }^{-}$simultaneously (Meybeck 1987).

End member identification and mixing calculation

As mentioned in the "Site description", three sources are considered to be potential sources that can affect the chemical compositions of groundwater in the CA, including LA, TA and itself. However, these aquifers have different wall rock compositions, and therefore, the groundwater from them can be identified through their chemical compositions, based on the fact that they are predominantly controlled by water-rock interactions under the condition without groundwater mixing (Sun and Gui 2011, Sun and Gui 2012; Gui et al. 2011).

As can be seen from Fig. 5, the groundwater samples have $\mathrm{Ca}^{2+} / \mathrm{Na}^{+}, \mathrm{HCO}_{3}{ }^{-} / \mathrm{Na}^{+}$and $\mathrm{Mg}^{2+} / \mathrm{Na}^{+}$ratios that range between the fields of evaporate dissolution and silicate weathering, and no sample shows contribution from carbonate dissolution. Therefore, contribution from TA is not expected, and the main contributors for the hydrochemistry of the groundwater in this study are considered to be LA and CA.

Factor score plots can provide important information about groundwater mixing and end member identification (Laaksoharju et al. 1999, 2008). Although they use principle component scores for solving this issue, here we use factor scores instead. It can be found in $Q-Q$ plots of factor scores (Fig. 6) that there are two inflection points in factor score 1 and 2 . And, according to these inflection points, the samples in scatter plots of factor scores (Fig. 7a) can be subdivided into three groups and three trends can be identified: 

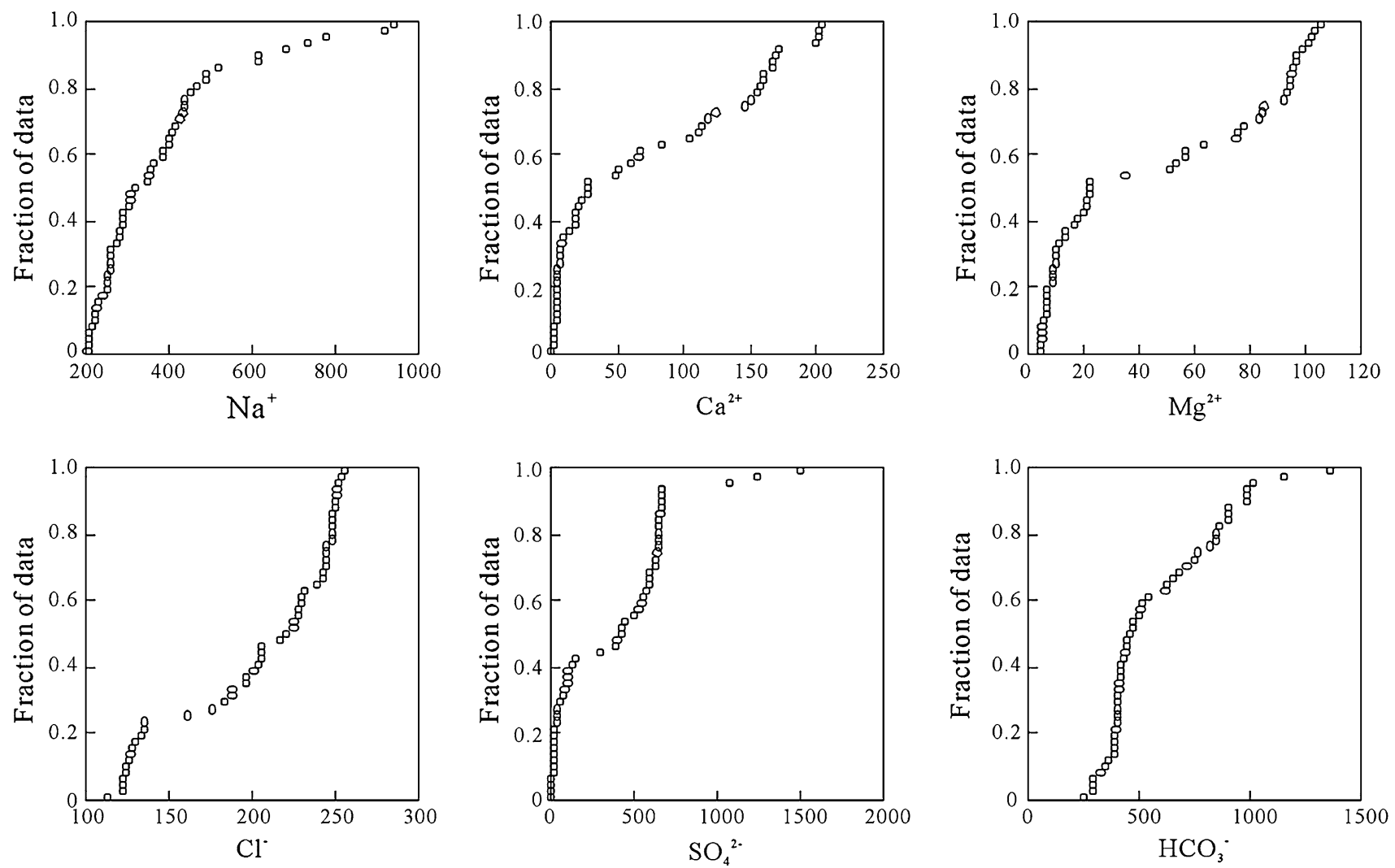

Fig. $3 Q-Q$ plots of major ion concentrations
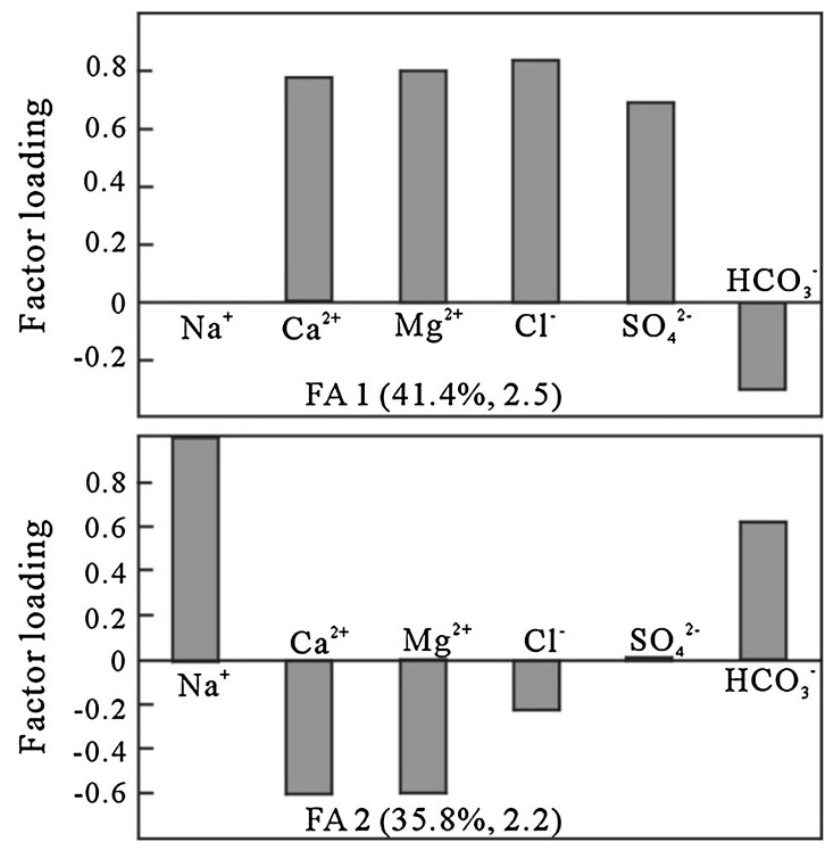

Fig. 4 Bar charts of factor loadings

G1, samples located between Q14 and Q11, which indicates lower degree of water-rock interactions (depletion of contributions from more soluble and silicate minerals); G2, samples located between Q14 and Q50, which indicates higher degree of water-rock interactions (enrichment of contributions from more soluble and silicate minerals); G3, samples located between Q14 and Q29, which indicates more contribution from more soluble minerals but less contribution from silicate minerals, and cannot be explained by different degrees of water-rock interactions. Moreover, because the contribution from TA is not important for the chemical compositions of the groundwater samples in this study, the trend from Q14 to Q29 is considered to be the express of groundwater mixing between LA and CA, because more carbonates can only be found in the wall rocks of the fourth aquifer in LA except for TA.

To confirm this consideration, major ion concentrations of two samples ( $\mathrm{T} 1$ and 2) reported by Gui and Chen (2007) during water inrush in 2001 have been analyzed simultaneously with the data in this study. It should be noticed that these two samples had been identified as mixing water supplied by LA and CA, because during the water inrush, the water table of LA is decreasing fast. As can be seen from Fig. 7a, these two samples are plotted near the field of G3 and located between sample Q11 and Q29, which is similar to the previous understanding that they are mixing water of LA and CA. 
Fig. $5 \mathrm{Na}^{+}$normalized $\mathrm{Ca}^{2+}{ }_{-}$ $\mathrm{HCO}_{3}{ }^{-}$and $\mathrm{Ca}^{2+}-\mathrm{Mg}^{2+}$ plots

Fig. $6 Q-Q$ plots of factor scores

Fig. 7 a Plots of factor scores and $\mathbf{b}$ mixing calculation using end members defined by factor analysis
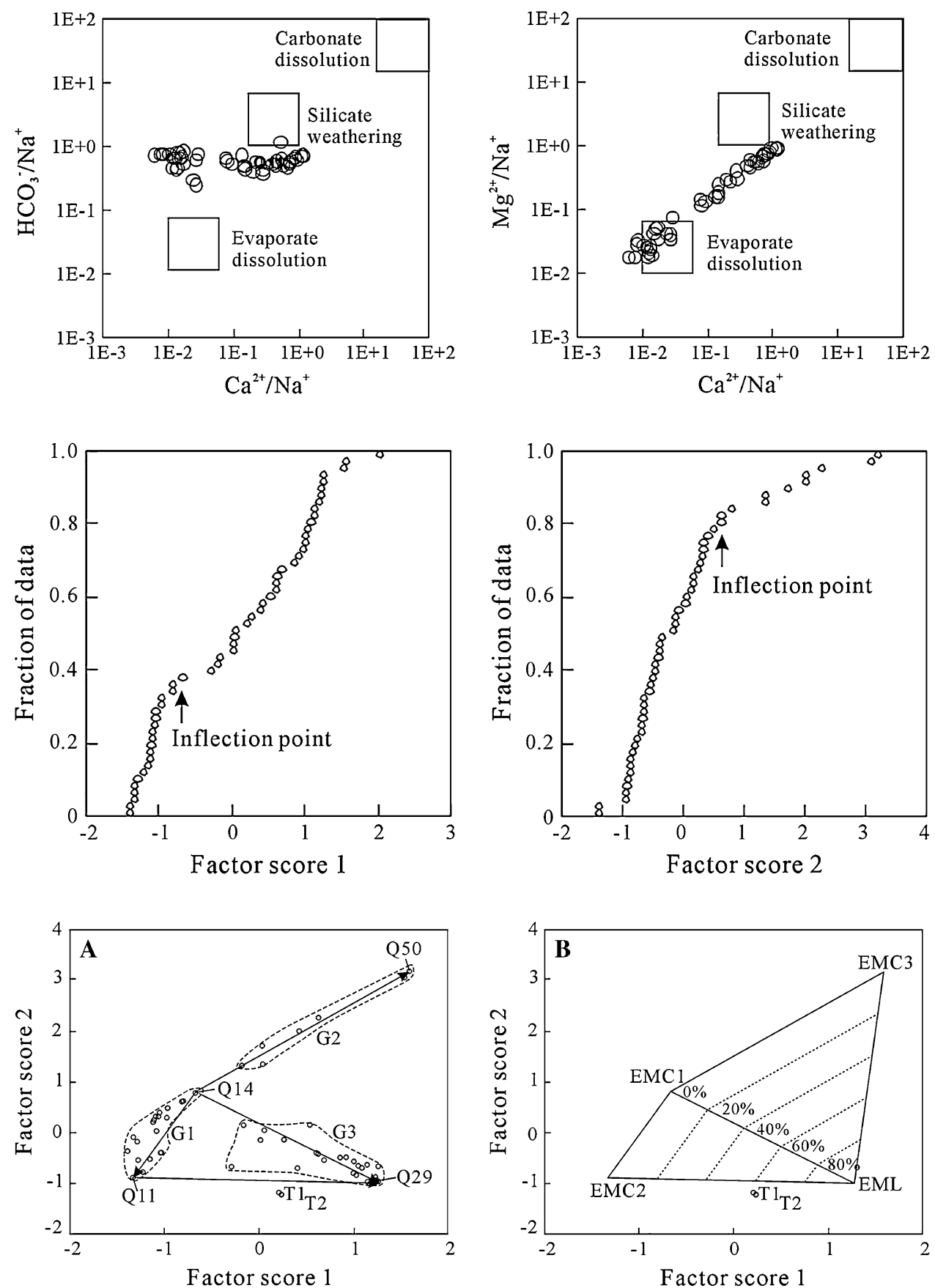

Therefore, the hydrochemistry of groundwater samples in this study can be explained by two kinds of hydrological mechanisms: different degrees of water-rock interactions, which is expressed by Q11-Q14-Q50 trend, another one is groundwater mixing between LA and CA, which is expressed by Q14/Q11-Q29 trend. Moreover, because the chemical compositions of the groundwater from CA have a broad range, samples including Q14, Q11 and Q50 are selected as end members of CA (EMC1, 2 and 3) and Q29 is selected as end member of LA (EML) (Fig. 7b).
It can be seen in Fig. 7a that G3 group samples are mixtures of Q11, Q14 and Q29. Therefore, the mixing calculations among the three samples were processed by two kinds of methods: one is mixing using Aquachem software and another is linear calculations of factor scores of end members. The results are listed in Table 2 and shown in Fig. 7b. As can be seen from the table and figure, these two kinds of methods give different results: the linear calculations suggest that the samples in 2011 (T1 and T2) have $\sim 60 \%$ contributions from the Q29 (EML), whereas the mixing calculations by Aquachem software suggest 44 
Table 2 Results of mixing calculations using Aquachem software

\begin{tabular}{lrrrrrl}
\hline End member & $\mathrm{Na}^{+}$ & $\mathrm{Ca}^{2+}$ & $\mathrm{Mg}^{2+}$ & $\mathrm{Cl}^{-}$ & $\mathrm{SO}_{4}^{2-}$ & $\mathrm{HCO}_{3}^{-}$ \\
\hline Q11 (EMC2) & 224 & 28 & 22 & 205 & 103 & 290 \\
Q29 (EML) & 206 & 201 & 102 & 249 & 663 & 399 \\
T1 (original) & 129 & 180 & 70 & 299 & 282 & 448 \\
T1 (58 \%) & 216 & 101 & 56 & 223 & 338 & 336 \\
T2 (original) & 128 & 179 & 72 & 302 & 289 & 452 \\
T2 (56\%) & 216 & 104 & 57 & 224 & 349 & 338
\end{tabular}

$\mathrm{T} 1(58 \%)$ and $\mathrm{T} 2(56 \%)$ are the results of mixing calculations by Aquachem software. 58 and $56 \%$ are the proportions of EMC2 obtained by mixing calculation

and $42 \%$ contributions from the EML. These differences suggest that not only the mixing, but also other processes (e.g. chemical reaction) must have been undertaken.

\section{Conclusions}

Major ion concentrations of groundwater samples from the $\mathrm{CA}$ in the Qidong coal mine, northern Anhui Province of China have been processed by statistical analysis for the understanding of their hydro-chemical characteristics and hydrological evolution, and the following conclusions have been made:

The groundwater samples are dominated by $\mathrm{Na}-\mathrm{SO}_{4}$ and $\mathrm{Na}-\mathrm{HCO}_{3}$ types, to a lesser extent, $\mathrm{Ca}-\mathrm{SO}_{4}$ and $\mathrm{Na}-\mathrm{Cl}$ types. $Q-Q$ plots of major ion concentrations suggest that they are originated from multi-sources, which is further supported by factor analysis that dissolution of more soluble minerals and weathering of silicate minerals are main contributors.

Plots of sodium-normalized calcium, magnesium and bicarbonate indicate that TA is not important for the hydrochemistry of the groundwater, whereas $Q-Q$ plots and scatter plots of factor scores imply that most of the samples are controlled by different degrees of water-rock interactions, whereas others have been affected by groundwater mixing, and mixing calculation of end members suggests that these samples have $20-100 \%$ contribution from LA.

The study demonstrated that statistical analysis of hydrochemistry can be used for understanding of the hydro-chemical and hydrological evolution of the groundwater system (e.g. water-rock interaction and groundwater mixing) and, during coal mining in the Qidong coal mine, the threats posed by LA should be taken seriously.

Acknowledgments This work was financially supported by National Natural Science Foundation of China (41302274 and 41373095) and the Natural Science Foundation of Anhui Province (1308085QE77).
Open Access This article is distributed under the terms of the Creative Commons Attribution License which permits any use, distribution, and reproduction in any medium, provided the original author(s) and the source are credited.

\section{References}

Cloutier V, Lefebvre R, Therrien R, Savard MM (2008) Multivariate statistical analysis of geochemical data as indicative of the hydrogeochemical evolution of groundwater in a sedimentary rock aquifer system. J Hydrol 353(3):294-313

Gui HR, Chen LW (2007) Hydrogeochemistric evolution and discrimination of groundwater in mining district. Geological Publishing House, Beijing

Gui HR, Sun LH, Chen LW, Chen S (2011) Rare earth element geochemistry of groundwater from a deep seated sandstone aquifer, northern Anhui province, China. Min Sci Technol 21(4):477-482

Johannesson KH, Stetzenbach KJ, Hodge VF (1997) Rare earth elements as geochemical tracers of regional groundwater mixing. Geochim Cosmochim Acta 61(17):3605-3618

Laaksoharju M, Skårman C, Skårman E (1999) Multivariate mixing and mass balance (M3) calculations, a new tool for decoding hydrogeochemical information. Appl Geochem 14(7):861-871

Laaksoharju M, Gascoyne M, Gurban I (2008) Understanding groundwater chemistry using mixing models. Appl Geochem 23(7):1921-1940

Long AJ, Valder JF (2011) Multivariate analyses with end-member mixing to characterize groundwater flow: wind cave and associated aquifers. J Hydrol 409(1):315-327

Meybeck M (1987) Global chemical weathering of surficial rocks estimated from river dissolved loads. Am J Sci 287(5):401-428

Morales-Casique E (2012) Mixing of groundwaters with uncertain end-members: case study in the Tepalcingo-Axochiapan aquifer, Mexico. Hydrogeol J 20(3):605-613

Nakaya S, Uesugi K, Motodate Y, Ohmiya I, Komiya H, Masuda H, Kusakabe M (2007) Spatial separation of groundwater flow paths from a multi-flow system by a simple mixing model using stable isotopes of oxygen and hydrogen as natural tracers. Water Resour Res 43(9):W09404. doi:10.1029/2006WR005059

Ramos-Leal JA, Martinez-Ruiz VJ, Rangel-Mendez JR, de la Torre MA (2007) Hydrogeological and mixing process of waters in aquifers in arid regions: a case study in San Luis Potosi Valley, Mexico. Environ Geol 53(2):325-337

Reimann C, Filzmoser P, Garrett RG (2005) Background and threshold: critical comparison of methods of determination. Sci Total Environ 346(1):1-16

Rueedi J, Purtschert R, Beyerle U, Alberich C, Kipfer R (2005) Estimating groundwater mixing ratios and their uncertainties using a statistical multi parameter approach. J Hydrol 305(1):1-14

Schramke JA, Murphy EM, Wood BD (1996) The use of geochemical mass-balance and mixing models to determine groundwater sources. Appl Geochem 11(4):523-539

Sun LH, Gui HR (2012) Establishment of water source discrimination model in coal mine by using hydrogeochemistry and statistical analysis: a case study from Renlou Coal Mine in northern Anhui Province, China. J Coal Sci Eng 18(4):385-389

Sun LH (2013) Statistical analysis of hydrochemistry of groundwater and its implications for water source identification: a case study. Arab J Geosci. doi: 10.1007/s12517-013-1061-8

Sun LH, Gui HR, Chen S (2011) Rare earth element geochemistry of groundwaters from coal bearing aquifer in Renlou coal mine, northern Anhui Province, China. J Rare Earths 29(2):185-192 
Valder JF, Long AJ, Davis AD, Kenner SJ (2012) Multivariate statistical approach to estimate mixing proportions for unknown end members. J Hydrol 460-461:65-76

Wigley TML, Plummer LN (1976) Mixing of carbonate waters. Geochim Cosmochim Acta 40(9):989-995

Yalcin MG, Tumuklu A, Sonmez M, Erdag DS (2010) Application of multivariate statistical approach to identify heavy metal sources in bottom soil of the Seyhan River (Adana), Turkey. Environ Monit Assess 164(1-4):311-322

Zhou J, Ma D, Pan J, Nie W, Wu K (2008) Application of multivariate statistical approach to identify heavy metal sources in sediment and waters: a case study in Yangzhong, China. Environ Geol 54(2):373-380 